\title{
Exploring the Ideal and Belief Education of College Students from the Perspective of Positive Psychology
}

\author{
Yingying Zhang* \\ Teachers College, Columbia University, New York, USA \\ *Corresponding author: Yingying Zhang, wushi.tang2@gmail.com
}

\begin{abstract}
This article mainly explores the ideal and belief education of college students based on the perspective of positive psychology. This article first explains the current situation of college students' mental health education, further elaborates the important role of ideal and belief education based on positive psychology, and finally points out how to realize the ideal and belief education vision among college students in the perspective of positive psychology for reference of relevant personnel.
\end{abstract}

Keywords: Positive psychology; College students; Ideal and belief education

Publication date: June 2021; Online publication: June 30, 2021

\section{Current status of mental health education for college students}

\subsection{Unclear goals of mental health education}

At present, China's higher education is one of the national key educations. The speed of higher education development has increased, and it has entered a stage of rapid development. The requirements for educators for higher education have also been raised. Compared with ordinary college students, the advantage of vocational college students is that they have special skills in which the purpose of higher vocational schools is to train students to develop these skills. However, compared to ordinary universities, its disadvantages are the low levels of cultural subjects and the lack of scientific rationality in these subjects. ${ }^{[1]}$ When college students plan their careers, social development demands higher requirements for college students in which they need to have skills and become highly skilled talents. Such conflicts lead to more prominent mental health problems among students and eventually, they fail their exams. Hence, when selecting colleges, students can only select higher vocational schools to learn skills. Some vocational students feel inferior, anxious, unable to appreciate their own strengths, lack of self-confidence, and lack of hope for progress. These psychological characteristics are completely different from those of college students. Therefore, the current psychological goal of middle school health education is to solve the psychological problems of most students such as low self-esteem, anxiety, and depression. The application of positive psychology in college education requires more attention in regard to the psychological state of the students, not only to correct students' mentality, but also to resolve their inferiority and anxiety while guiding them to be positive without using unclear psychological education attitudes. In regard to students in higher vocational colleges, the country would demand more highly skilled talents in the future. Therefore, it is necessary to focus on the psychological state of the students and establish appropriate mental health education goals. 


\subsection{Mental health education focuses on solving psychological problems}

Traditional mainstream psychology such as behaviorism, psychoanalysis, and cognitive psychology are all aimed at "people with psychological problems." ${ }^{2]}$ This negative mental health education model neglects the positive strength of an individual. At present, the concept of mental health education in higher vocational colleges is largely based on the traditional mainstream psychology which targets psychological problems. Mental health educators are like "firefighters" who extinguish fires whenever there is one. The purpose of this passive mental health education model is to solve problems but neglect the exploration of high school students' personal interests, stimulating personal growth motivation, and helping them find meaning in life. In other words, the mental health education lacks concepts that can prevent problems before they occur. The number of students with mental illnesses in higher vocational colleges is relatively high. This requires adjusting the focus of mental health education and expanding its scope. Positive psychology believes that there are two mutually exclusive forces in everyone's minds. One of it is a positive force such as optimism, perseverance, gratitude, humor, courage, creativity, etc., while the other is a negative force such as depression, fear, and anxiety. When the negative force dominates, individuals would exhibit negative personality traits such as low self-esteem, anxiety, and fear, but when the positive force dominates, they would exhibit positive personality traits such as gratitude and kindness, teamwork, creativity, and righteousness. Practice has proved that positive personality traits would contribute to people's healthy development. Positive personality traits would continuously strengthen the inner positive power and translate it into their personal life, study, and work habits. In higher vocational mental health education, teachers are required to inspire the positive power of students with diverse personalities, guide them to continuously enhance their own advantages, and apply positive power to life, work, and study.

\subsection{Single feature of mental health education}

Traditionally, mental health education reflects the simple solution to students' psychological problems. The curriculum of mental health education involves conducting psychological investigations on freshmen, providing case consultation, imparting mental health knowledge to students, intervening with psychological problems, and creating a positive attitude. Setting up a scientific, reasonable, and effective innovation mechanism, creating a positive campus cultural atmosphere, stimulating students' skills in discovery, research, and problem-solving, persistently cultivating learning, practicing skills, and caring about the growth of students' talents form the design psychology of higher vocational schools. ${ }^{[3]}$ Mental health educators in higher vocational colleges need to actively create opportunities in order to effectively encourage college students in their participation of clubs and organizations on campus as well as social activities. In order to achieve excellent results, leisure interests, school learning interests, future career interests, etc. should be understood while stimulating curiosity, gaining more knowledge, and becoming experts in specific fields.

\section{Practical significance of strengthening the ideal and belief education of college students}

\subsection{Contribute to enhancing college students' sense of struggle in the journey of "realizing their dreams"}

At present, China is facing a complex environment with poor trade, technology, and political situations. The journey to realize the great Chinese dream of rejuvenation is full of thorns. It is necessary to respond to "trade wars" and "technological wars" with a strong sense of struggle. In this struggle, there is a need to emphasize on political attitudes and grasp political methods. As the primary idealist of the "Chinese Dream," contemporary universities should have a sense of crisis and being prepared for danger in times of peace, having struggle consciousness at all times, establish national security awareness, as well as strengthen the 
concept of "One China." It is also important to have firm political stands, safeguard the great cause of the reunification of the motherland, and having the bravery to fight against all evil forces in the promotion of world peace and development. ${ }^{[4]}$

\subsection{Contribute to arousing the mission of college students while adhering to their ideals and beliefs}

The main notion of the ideal and belief education for college students is to guide students to establish Marxist beliefs, common ideals of socialism with Chinese characteristics, and the lofty ideals of communism in order to strengthen patriotism, collectivism, socialism, national outlook, and cultural outlook among students as well as to strengthen their awareness in serving people. The education of ideals and beliefs among college students in the new era is the top priority in the field of ideology. College students are the builders and successors of the cause of socialism and the hope of the nation. Deviations in students' ideology will affect the security of the entire national ideological field. Hence, there is a need to improve the education of ideals and beliefs for college students, guide them to cast their personal growth into the four pillars of socialist construction in the new era, as well as clarify the overall layout, strategic layout, and strategic steps of the country which will help to arouse the mission of college students while adhering to their ideals and beliefs. College students should also be urged to serve and build a strong country. ${ }^{[3]}$

\subsection{Conducive to guide college students in establishing scientific beliefs and pursuing rational values}

"The education of ideals and beliefs does not only provides students with knowledge, but also functions to provide correct ideals and beliefs as well as scientific beliefs." In the process of providing direction of scientific beliefs, it is inseparable from the use of scientific theories. This becomes a form of knowledge supply and promotes the process of students' knowledge internalization which would guide them to pursue lofty ideals. General Secretary Xi Jinping pointed out that "Without Marxist beliefs and communist ideals, there would be no Communist Party of China and no socialism with Chinese characteristics."

Strengthening the education of college students' ideals and beliefs is helpful to guide them in shaping upright souls with firm ideals and beliefs as unremitting efforts for the lofty ideals of human liberation.

\section{Ways to realize college students' ideal and belief education based on the perspective of positive psychology}

\subsection{Establishing a positive education concept}

Generally, positive psychology has a more profound impact on students and teachers while traditional psychology education emphasizes on solving problems after discovering them. Such an approach is a negative manifestation in itself. All traditional mental health teaching methods apply negative psychology to a certain extent which affects the psychological state of teachers and students in the process. Therefore, major changes are needed to eliminate these effects and effectively carry out the positive psychology education. The application of positive psychology first requires a conceptual change in which a healthy and progressive psychological education concept needs to be formed. ${ }^{[3]}$ The examples and selected cases provided by the teachers in the course of teaching should leave positive impressions. It is necessary to stimulate interest and further diversify teaching contents so that students are able to form positive emotions and develop their enthusiasm. Finally, in psychological counseling, teachers should explore the students' noble qualities and personality potentials, help them to build self-confidence, guide them to form positive concepts, and reduce the impact of negative psychology. Traditional psychology emphasizes more on the changes in moral education, the persuasiveness of students' psychological problems, and the elimination of negative psychology. In fact, when a student has psychological problems, from the perspective of positive psychology, the student's positive psychology is not enough to help him or her to form healthy 
concepts. It is a challenge for these traditional psychological education concepts to exert a greater effect on these students. Only by stimulating their positive emotions, only then can the problems be solved fundamentally.

\subsection{Strengthening the interaction between society and schools to increase employment opportunities}

The society should strengthen exchanges with schools to provide more employment opportunities for college students. On the other hand, social media should promote the bright side of the society, transmit positive energy, guide the society to form good morals, and exert positive awareness. In order to implement the education of ideals and beliefs among college students in the new era, the government must play a policy-driven role. It is necessary to strengthen policy guidance, formulate guidelines and policies, provide correct theoretical guidance, implement relevant measures, and strengthen the construction of a socialist moral system. The improvement of family environments is supplementary to the ideal and belief education for college students in this new era whereas optimizing the school environment is the key to this education.

\subsection{Innovation of ideal and belief education methods}

In the ideal and belief education of college students, a combination of theory and practice can be adopted to fully integrate course teaching, program design, and homework guidance into all links of this education. In regard to the curriculum, the changes of college students' thinking and behaviors in the process of learning should be better understood. In order to promote the effectiveness of classroom education, educational plans should also be coordinated in a timely manner, the quality of education as well as the students' quality and quantity should be improved. Secondly, in order to solve the cognitive shortcomings and issues of modern college students' ideals and beliefs, it is necessary to focus on teacher-student communication to establish good teacher-student emotions. There is also a need to narrow the generation gap between teachers and students by adjusting and solving the issue of the exchange system while analyzing the status quo, political literacy, and moral defects of college students. The ideal and belief education in universities should further implement the method of establishing network platforms to utilize the functions of modern educational tools in conducting the education for students through the internet. Through this way, teachers can share with their students the platforms that are related to ideal and belief education and further promote the advancement of this education over time. In addition to that, in the universities' education of ideals and beliefs, students should be allowed the right to speak on the internet while reducing and preventing the intrusion of internet culture on money worship in their thinking.

\section{Conclusion}

In short, the ideal and belief education of college students based on the perspective of positive psychology should construct positive educational concepts, strengthen the interaction between enterprises and society, increase employment opportunities for college students, and innovate methods of this education.

\section{Disclosure statement}

The author declares no conflict of interest.

\section{References}

[1] Ablimiti A, 2019, Mental health of poor college students under positive psychology. Think Tank Times, (41): 295-6.

[2] Ou Y, 2019, On the effective guidance of ideological and political education in colleges and universities 
from the perspective of positive psychology. Talent, (27): 54.

[3] Lu YL, 2019, Analyzing the psychological crisis prevention of college students from the perspective of positive psychology. Times Report, (07): 254-6.

[4] Li T, 2020, From the perspective of positive psychology to explore the correct way to lead college students' consumption outlook. Marketing circles, (11): 178-9.

[5] Wang YQ, 2020, Research on the learning motivation of vocational college students from the perspective of positive psychology. Talent, (14): 156.

[6] Cheng W, 2019, Exploring how to improve the core literacy of higher vocational students from the perspective of positive psychology. Joint Journal of Tianjin Vocational Colleges, 21(11): 93-6. 